\title{
Modular-Multilevel Inverter based on Various Switching Modules for Harmonic Elimination in HVDC
}

\author{
P. Rajasekeran, L. Chitra, D. Saranya, N.P. Gopinath
}

\begin{abstract}
For transmitting the power and reducing harmonic distortion at long distance HVDC system in industrial application the Modular Multilevel Converter (MMC) is utilized. While contrasted and AC system, HVDC system utilized this technique as a result of its cost effective function, effectiveness of high transmission rate. MMC is for the most part utilized for reducing the filter size. In industrial application, it is extensively used for voltage balance, control of circuiting current at each arm and reduces the voltage ripple. In this paper MMC based various switching modules are used to mitigate the Total Harmonics Distortion (THD) that presents in the HVDC line. MMC has used in HVDC and LVDC applications. MMC is analyses and concludes the advantages and enhancement of converter modulation for reduce the voltage ripple.
\end{abstract}

Keywords: HVDC, Modular Multilevel Converter, Switching Modules, Total Harmonic Distortion.

\section{INTRODUCTION}

HvDC transmission system is progressed to AC as a result of lengthy distance bulk transmission system, short circuit level and long distance underground cable system. The converters are used for transmitting from the high voltage AC is buck and transmit the voltage to long distance and conveyed at receiving end [1-2]. The use of converter is MMC for lessening the noise, regulate the DC voltage and reducing the circulating current. The operation and performance of the MMC is same as cascaded H-bridge inverter. Though, MMC requires less input sources than cascaded H-bridge inverter. The MMC has lots of advantages over than Voltage Source Converter (VSC) [3-4]. At the time of fast recovery and fault from short circuit it leads to current limiting ability and there is no need of filter to achieve high gain in the system. The attained output voltage gain is less because of high system switching frequency (Fs) and overall switching frequency. It has the benefits of absence of filters,

Revised Manuscript Received on December 16, 2019

P. Rajasekeran *, Professor, Department of Electrical and Electronics Engineering, Aarupadai Veedu Institute of Technology, Vinayaka Missions Research Foundation, Chennai, Tamilnadu, India.

Dr. L. Chitra, Associate Professor \& Head, Department of Electrical and Electronics Engineering, Aarupadai Veedu Institute of Technology, Vinayaka Missions Research Foundation, Chennai, Tamilnadu, India.

D. Saranya, Assistant Professor, Department of Electrical and Electronics Engineering, Aarupadai Veedu Institute of Technology,Vinayaka Missions Research Foundation, Chennai, Tamilnadu, India.

N.P. Gopinath, Assistant Professor, Department of Electrical and Electronics Engineering, Aarupadai Veedu Institute of Technology, Vinayaka Missions Research Foundation, Chennai, Tamilnadu, India.

protection from short circuit, reduces noise in the system, and fault compensation [5-6]. The multi-terminal DC presents the vision of lattice interconnection between regional Power Systems (PS) and Renewable Energy Generation (REG) which increases the reliability of both AC and DC system improves the adaptability, power dispatch and productive use of links of cables and converter in HVDC system [7]. The highlights of MMC is modularity and adaptability to meet the voltage level necessity, deduce the voltage rating and lessen the burden over the switches and capacitors, upgrade the nature of intensity and deficiency blocking ability to improve the fault interference [8].

The subfamily of multilevel converter is multi modular converter has widely used in high voltage application, medium voltage drives and static synchronous compensator. For high power applications, the conventional inverters are planned with series connected switching devices. Connecting the switches in series will lead the enhancement the stress across the switches. Higher voltage levels are found out using more number of switching devices [9-11]. If the number of switching devices increases, generation of gate signals for the switching devices will be difficult. Thus, the MMC is a promising converter topology in the near future.

\section{PROPOSED METHOD}

The MMC consists of many modules that are connected by inductor and it controls the circulating phase current. The MMC widely has used in HVDC transmission system, FACTS and high power motor applications. The advantages of the MMC are, controlling the current which circulates around the circuit and balancing voltage across the capacitor. The capacitor energy doesn't increases during the time of current flows through the arm in -ve direction. More than one $\mathrm{SM}$ is connected to inductor which forms an arm. The two arm are connected it is defined as one phase of the inverter. The SM is further subdivided into half bridge SM circuit, and full bridge SM circuit. Figure 1 shows the MMC circuit diagram in HVDC system. 


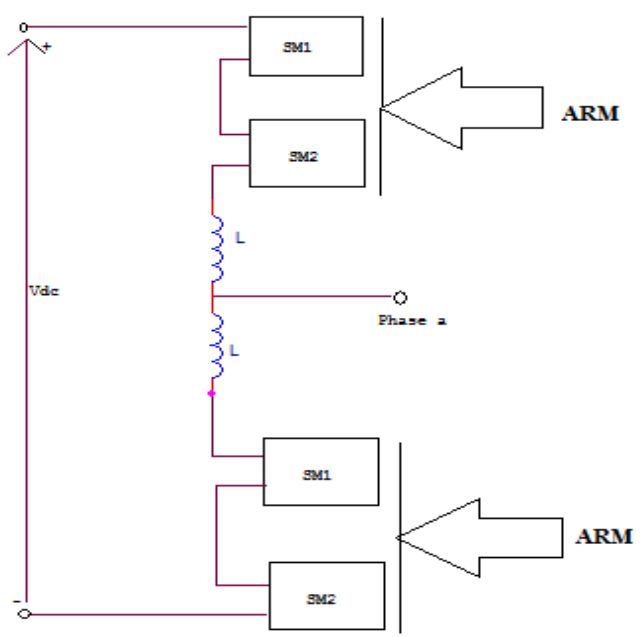

Fig. 1.MMC Circuit Diagram

The half bridge circuit of switching modules is shown in fig. 1. In half bridge have only two switches to control the voltage ripple. Vout $=0$ or Vcapacitor, depends on the switching configuration. The capacitor energy increases during the time of current flows through it in +ve direction. This is the nature of the capacitor. When the switch S1 is ON then the module is an active position and Vout= Vcapacitor and capacitor states may depends on current flows in the module.

The switch $\mathrm{S} 2$ is ON the state of the switching modules is inactive and the Vout $=0$ and the voltage across the capacitor is stable and the state is neither charge nor discharge. Both $\mathrm{S} 1$ and $\mathrm{S} 2$ of the half bridge module is OFF current will flow through freewheeling diode. The switching modules count in every phase determines the levels of the voltage. The full bridge converter four switches and switching losses is increased compared to twice the half bridge switching modules but is deals with the dc fault. The voltage of the switching modules is depends on the states of the insulated gate bipolar transistor.

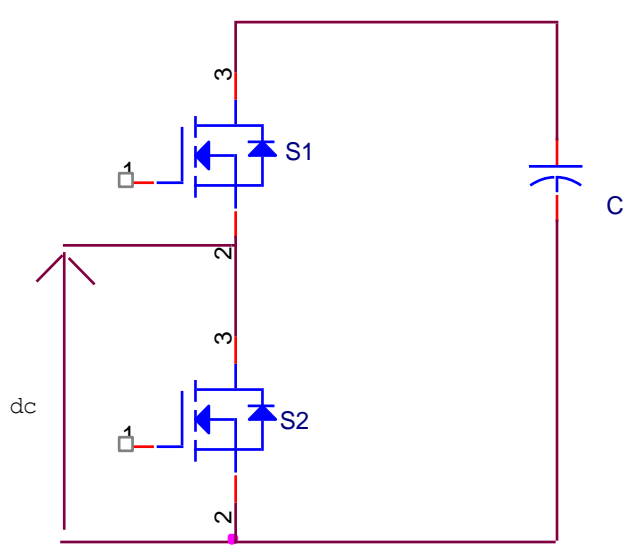

Fig. 2.Half Bridge Switching Module of MMC Circuit Diagram

In MMC the current flows in the arm through the capacitor of the switching modules. The switching frequency of the power devices is less for decreasing the number of transition. The mathematical modeling of MMC in higher and lower arm and current in lower arm of the phase converters. The current in the higher and lower phase arm is sinusoidal and which is $1 / 3^{\text {rd }}$ of $i_{\mathrm{DC}}$ current. The current in the DC link during stable condition is divided equally to three phase inverter leg.

$$
\begin{aligned}
& P=\frac{3}{2}\left(V_{q} i_{q}+V_{d} i_{d}\right) \\
& Q=\frac{3}{2}\left(V_{q} i_{d}-V_{d} i_{q}\right)
\end{aligned}
$$

The carrier disposition pulse width modulation has $\mathrm{n}$ similar triangular and it is symmetrical with zero. The compare of phase carrier voltage with reference and produce the pulse generation and fed into the MMC. The carrier wave is classified into PD, POD and APOD, The asymmetrical distribution of voltage ripples in capacitor that enhances the harmonics of ac voltage and high circulating current. The multi modular converter (MMC) based on active power filter uses the alternate phase opposition disposition pulse width modulation for harmonics reduction. Due to capacitor voltage fluctuation in modules reason for the even order harmonics in system of multi modular converter.

Figure 5 shows the carrier waveform of APOD. This converter presents an advanced repetitive controller for mitigating the circulating current of MMC. This repetitive control method is simple and substantially to eliminates the harmonic components with improved transient performance, while the voltages of SM capacitors are kept well balanced. Alternate phase opposition disposition method is utilized in this paper for reducing the transmission line losses with the help of MMC. Pulse generated by the APOD is comparing with two carrier signal. Each carrier signal has the difference of $180^{\circ}$ phase. Two carrier waves have same frequency and same amplitude but phase difference is different. The APOD improve the performance of modular converter based transmission system.

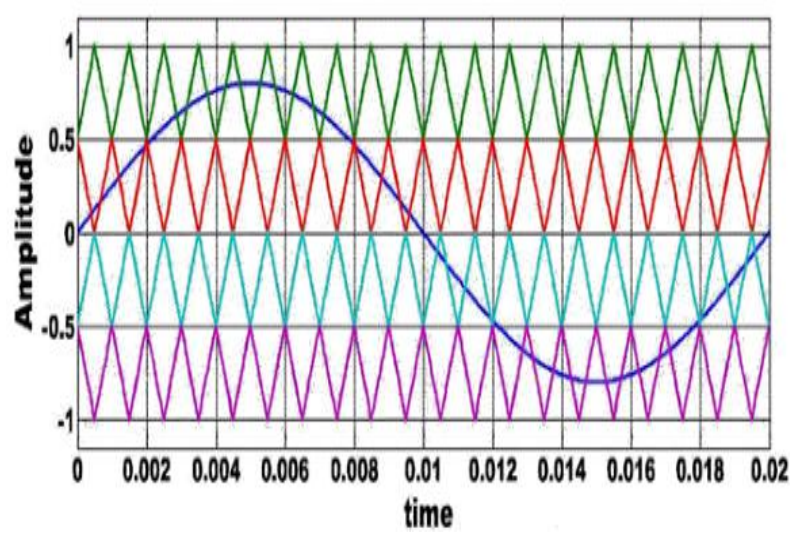

Fig. 3.APOD waveformCircuit Diagram

\section{SIMULINK ANALYSIS}

The proposed half bridge switching module of MMC with APOD control method is 
implemented and the results are verified in MATLAB/Simulink. The fig.4. shows the overall simulink diagram of the proposed system. Fig.5. shows the 7level output voltage and current of the MMC. Output voltage is about $380 \mathrm{~V}$, output current is about 10amps. THD value of the half bridge MMC is shown in fig.6. and its value is about $3.98 \%$.

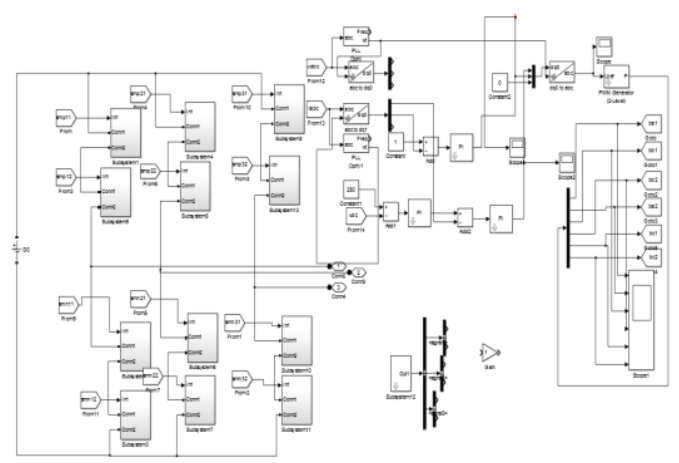

Fig. 4. Simulink model of the proposed system

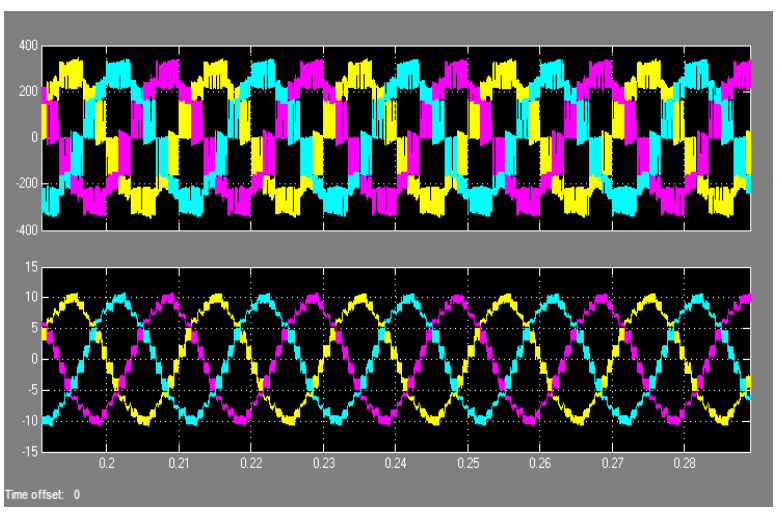

Fig. 5.Output voltage and current of half bridge MMC

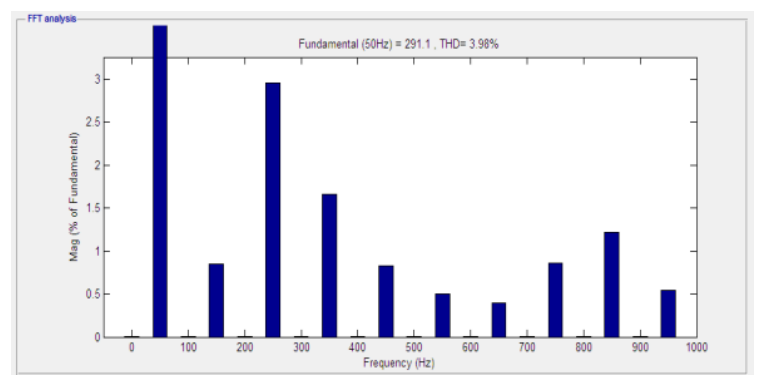

Fig. 6.\% THD

\section{CONCLUSION}

This paper deals with the half bridge switching module of MMC with APOD control method. The modularity observation from the switching modules of MMC to the system level has been examined on various presented categories. The modularity concept, half bridge switching module topologies have been analyzed and thorough comparison of switching module topologies for high-control applications has been displayed for each modular converter class. APOD is generates the pulses to improve the output levels of the MMC. From the result, attained 7level output voltage and THD is about $3.98 \%$ are verified using MATLAB/Simulink.

\section{REFERENCES}

1. C., Chen, G.P. Adam, S. Finney, J. Fletcher, and B. Williams, "H-bridge modular multi-level converter: control strategy for improved DC fault ride-through capability without converter blocking", IET Power Electronics, vol.8, no.10, pp.1996-2008, 2015.

2. Y. Chen, S. Zhao, Z. Li, and Y. Kang, "Multi-object control of an isolated DC-DC modular multilevel converter”, IET Power Electronics, vol. 11, no. 8, pp.1338-1349, 2018.

3. L. Xiao, Y. Li, H. Xiao, Z. Zhang, and Z. Xu, "Electromechanical Transient Modeling of Line Commutated Converter-Modular Multilevel Converter-Based Hybrid Multi-Terminal High Voltage Direct Current Transmission Systems”, Energies, vol. 11, no. 8, p.2102, 2018

4. S. Song, Y. Hu, K. Ni, J. Yan, G. Chen, H. Wen, and X. Ye, "Multi-port high voltage gain modular power converter for offshore wind farms", Sustainability, vol. 10, no.7, pp.2176, 2018.

5. A. Nami, J. Liang, F. Dijkhuizen, and G.D. Demetriades, "Modular multilevel converters for HVDC applications: Review on converter cells and functionalities", IEEE Transactions on Power Electronics, vol. 30, no. 1, pp.18-36, 2015.

6. C. Verdugo, J.I. Candela, F. Blaabjerg, and P. Rodriguez, "Three-Phase Isolated Multi-Modular Converter in Renewable Energy Distribution Systems", IEEE Journal of Emerging and Selected Topics in Power Electronics, 2019.

7. Y.U.A.N. Yubo, L.I. Peng, K.O.N.G. Xiangping, L.I.U. Jiankun, L. I Qun, and W.A.N.G. Ye, "Harmonic influence analysis of unified power flow controller based on modular multilevel converter", Journal of Modern Power Systems and Clean Energy, vol. 4, no. 1, pp.10-18, 2016.

8. L. Zhang, Y. Zou, J. Yu, J. Qin, V. Vittal, G.G. Karady, D. Shi, and Z. Wang, "Modeling, control, and protection of modular multilevel converter-based multi-terminal HVDC systems- a review", CSEE Journal of Power and Energy Systems, vol. 3, no. 4, pp.340-352, 2017.

9. Z. Wu, J. Chu, W. Gu, Q. Huang, L. Chen, and X. Yuan, "Hybrid Modulated Model Predictive Control in a Modular Multilevel Converter for Multi-Terminal Direct Current Systems", Energies, vol. 11, no. 7 , pp.1861, 2018

10. N. Vijayalakshmi, "Photovoltaic Fed Multilevel Inverter Design Using PODPWM Technique for Improved Power Quality", International Journal of Advances in Signal and Image Sciences, Vol. 5, No. 1, pp.8-14, 2019.

11. M. Jayabalan, B. Jeevarathinam, and T. Sandirasegarane, "Reduced switch count pulse width modulated multilevel inverter", IET Power Electronics, vol. 10, no. 1, pp.10-17, 2017.

\section{AUTHORS PROFILE}

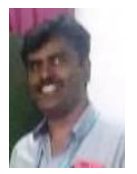

P. Rajasekaran is currently working in the EEE department of Aarupadai Veedu Institute of Technology. He obtained her B.E in EEE and M.E Degrees in Power Electronics and Drives. He is currently pursuing his $\mathrm{PhD}$ Her area of interests includes power electronics related to the renewable energy. $\mathrm{He}$ is also the vice-principal Administration at AVIT.

L. Chitra is an Associate Professor and Head in the department of EEE at Aarupadai Veedu Institute of Technology. She received her Bachelor Degree in Electronics and Instrumentation Engineering. She received her Master's Degree in Power Electronics and Drives in Anna University. She completed her PhD in Sathyabama Institute of Science and Technology in the field of Micro Electro Mechanical Systems for sensor design. Her research area includes MEMS, Renewable Energy, Process control, Sensors and Smart Sensors. She has published more than fifteen papers in International Conferences and Journals. She has a teaching experience of more than 18 years. She has received MNRE fund of Rs.1,50,000 for National Conference on Emerging Trends in New Renewable Energy Sources in the year 2014. She has also received a fund of Rs.1,00,000 from Unnat Bharat Abhiyan for Mobile Reverse osmosis based water purification system using Solar PV source for rural India in year 2019. She has also received a fund of Rs.50,000 from Unnat Bharat Abhiyan for DC Micro Grid based Solar PV generation to supply power to street lamp and common utilities in a village.

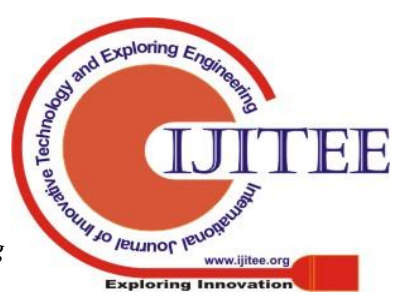


D. Saranya She received her B.E in Electrical and Electronics Engineering (2007) from Thirumalai Engineering College and M.Tech in Power Electronics \& Drives (2014) from SRM University. She is research scholar in Department of Electrical Engineering, Vinayaka Missions Research Foundation. Her research interests include Renewable Energy System. She is currently a member of ISTE.

N.P.Gopinath, He received his B.E in Electrical and Electronics Engineering (2009) from Noorul Islam College of Engineering and M.Tech in Power Electronics \& Drives (2013) from SRM University. He has more than 10 publications in the field of Power Electronics. He is research scholar in Department of Electrical Engineering, Vinayaka Missions Research Foundation. His research interests include Control System Applications to Power Electronics. 